\title{
PERSEPSI MASYARAKAT DAN DAMPAK SOSIAL EKONOMI TERHADAP LAHAN BEKAS TAMBANG TIMAH SEBAGAI KAMPOENG REKLAMASI AIR JANGKANG DI DESA RIDING PANJANG KABUPATEN BANGKA
}

\author{
COMMUNITY PERCEPTION AND SOCIAL-ECONOMIC IMPACTS ON THE USED \\ LAND OF TIN AS A KAMPOENG RECLAMATION OF RANGE WATER \\ IN THE RIDING PANJANG VILLAGE, BANGKA DISTRICT
}

\author{
${ }^{1}$ Vinda Asparita, ${ }^{1}$ Fournita Agustina dan ${ }^{1}$ Yudi Sapta Pranoto \\ ${ }^{1}$ Program Studi Agribisnis, Universitas Bangka Belitung \\ email : vindaasparita@gmail.com
}

\begin{abstract}
ABSTRAK
Kegiatan penambangan tidak hanya menimbulkan dampak yang terjadi di lokasi tambang tetapi juga lingkungan di sekitarnya, sehingga diperlukannya reklamasi. Penelitian ini bertujuan untuk mendeskripsikan persepsi masyarakat terhadap keberadaan Kampoeng Reklamasi Air Jangkang serta mendeskripsikan dampak sosial ekonomi masyarakat terhadap keberadaan Kampoeng Reklamasi Air Jangkang. Penelitian ini dilaksanakan pada bulan September 2019 sampai dengan bulan September 2020 di Desa Riding Panjang Kecamatan Merawang Kabupaten Bangka. Metode yang digunakan dalam penelitian ini adalah metode survei. Sedangkan metode penarikan contoh yang digunakan dalam penelitian ini menggunakan Purposive Sampling. Jumlah sampel yang diambil dalam penelitian ini sebanyak 93 sampel yang merupakan masyarakat Desa Riding Panjang. Metode analisis yang digunakan adalah metode deskriptif kualitatif dengan skala Likert. Hasil penelitian menunjukkan bahwa persepsi masyarakat terhadap lahan bekas tambang sebagai Kampoeng Reklamasi adalah sangat setuju dengan angka indeks sebesar 82,4 persen meliputi tahapan pra reklamasi, 81,4 persen meliputi pelaksanaan pembangunan Kampoeng Reklamasi dan angka indeks sebesar 88,8 persen meliputi keberhasilan pembangunan Kampoeng Reklamasi. Dampak sosial yang terjadi antara lain berdampak positif baik pada kondisi lingkungan dan keamanan masyarakat sekitar area reklamasi. Dampak ekonomi yang ditimbulkan adalah berdampak positif pada pendapatan masyarakat dan penyerapan tenaga kerja.
\end{abstract}

Kata Kunci : Kampoeng Reklamasi, Lahan Tambang, Masyarakat, Persepsi,

\section{PENDAHULUAN}

Kepulauan Bangka Belitung
merupakan salah satu provinsi yang
memiliki cadangan timah dan sebagai
penghasil timah terbesar di Indonesia.
Kegiatan pertambangan merupakan kegiatan
yang banyak ditemukan di daerah Bangka
Belitung. Penambangan timah di
Kepulauan Bangka Belitung telah
berlangsung sejak era kolonial Belanda dan
masih terus berlangsung sampai saat ini
(Inonu, 2013).

Kepulauan Bangka Belitung merupakan salah satu provinsi yang memiliki cadangan timah dan sebagai penghasil timah terbesar di Indonesia. yang banyak ditemukan di daerah Bangka Belitung. Penambangan timah di Kepulauan Bangka Belitung telah masih terus berlangsung sampai saat ini (Inonu, 2013). 
Saat ini banyak lahan bekas tambang yang dibiarkan terbuka dan tanpa adanya pengelolaan kembali. Dalam upaya memperbaiki lingkungan yang rusak akibat aktivitas penambangan, lahan bekas tambang harus direklamasi. Untuk itu diperlukan adanya suatu kegiatan reklamasi sebagai upaya pelestarian lingkungan agar tidak terjadi kerusakan lebih lanjut. Dengan reklamasi tersebut diharapkan akan mampu memperbaiki ekosistem yang rusak sehingga dapat pulih dan lebih baik dibandingkan kondisi semula. Dan salah satu cara yang dapat dilakukan adalah dengan melakukan reklamasi lahan bekas tambang timah. Reklamasi merupakan usaha memperbaiki atau memulihkan kembali lahan dan vegetasi dalam kawasan hutan yang rusak sebagai akibat kegiatan usaha pertambangan dan energi sehingga dapat berfungsi kembali secara optimal.

Air jangkang merupakan salah satu kawasan yang terletak di Desa Riding Panjang, Kecamatan Merawang, Kabupaten Bangka. Kampoeng Reklamasi Air Jangkang sebagai salah satu lahan pasca tambang yang dibiarkan selama \pm 5 tahun, kemudian dijadikan kawasan reklamasi oleh PT TIMAH Tbk dengan luas \pm 31 ha. PT TIMAH Tbk berupaya menjadikan lahan pasca tambang bermanfaat bagi kegiatan sosial ekonomi masyarakat dalam jangka panjang. sehingga tidak hanya menjadikan lahan kritis sebagai lahan pertanian tetapi juga bisa menjadikan lahan reklamasi sebagai destinasi wisata serta sebagai tempat beredukasi.

Kampoeng Reklamasi ini merupakan lahan bekas tambang timah Izin Usaha Pertambangan (IUP) milik PT TIMAH Tbk sesuai dengan Peraturan Pemerintah Republik Indonesia Nomor 78 Tahun 2010 Tentang Reklamasi dan Pasca tambang pasal 2 ayat 1 menyatakan bahwa pemegang Izin Usaha Pertambangan (IUP) wajib melaksanakan reklamasi. Total area lahan reklamasi seluas \pm 31 ha, yang terdiri dari 3 klaster dan PPS (Pusat Penyelamatan Satwa). Klaster pertama diisi zona tanaman pelawan dan zona buah-buahan, klaster zona peternakan dan nursery, serta klaster ketiga adalah zona penelitian.
Berdasarkan uraian diatas, maka perlu diteliti yaitu mengenai bagaimana persepsi masyarakat terhadap lahan bekas tambang sebagai Kampoeng Reklamasi Air Jangkang serta bagaimana dampak sosial ekonomi bagi masyarakat terhadap Kampoeng Reklamasi Air Jangkang. Tujuan dari penelitian ini untuk mendeskripsikan persepsi masyarakat dan dampak sosial ekonomi masyarakat terhadap Kampoeng Reklamasi Air Jangkang di Desa Riding Panjang Kecamatan Merawang Kabupaten Bangka. 


\section{METODE PENELITIAN}

\section{Kerangka Pemikiran}

Kerangka pemikiran dalam penelitian ini dapat dilihat pada Gambar 2.

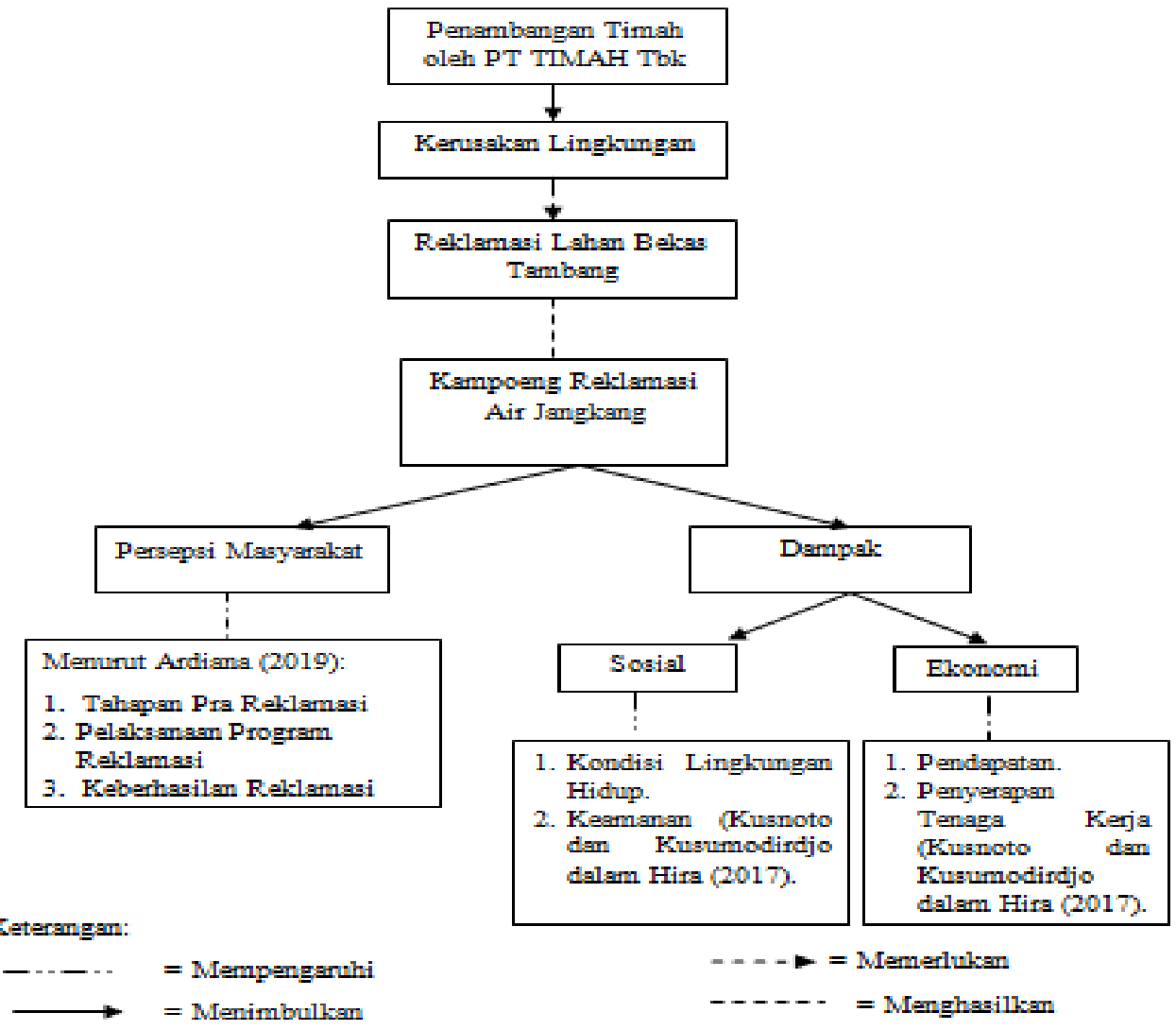

Gamber 2. Skema Keranglea Pemikiran Persepoi Masyaalex Dan Dempal Social Eloonomi Terbadap Laban Belas Tambang Kampoeng ReElamasi Air Janglang Di Desa Ríling Panjang

Berdasarkan gambar 2. Dapat dijelaskan bahwa mulainya penambangan timah yang dilakukan PT TIMAH Tbk di Air Jangkang menyebabkan kerusakan lingkungan yang terjadi pada sekitar tempat penambangan. Dengan terjadinya kerusakan lingkungan maka di butuhkan reklamasi lahan bekas tambang yang bertujuan untuk memperbaiki atau memulihkan kembali lingkungan yang rusak akibat aktivitas penambangan agar berfungsi secara optimal. Setelah di reklamasi, lahan bekas tambang ini kemudian diolah menjadi Kampoeng Reklamasi Air Jangkang sebagai tempat destinasi wisata dengan konsep Ecopark. Dengan adanya keberadaan Kampoeng Reklamasi ini menimbulkan persepi masyarakat dan dampak terhadap sosial ekonomi masyarakat sekitar area kegiatan reklamasi.

\section{Pengumpulan Data}

Penelitian ini dilaksanakan di Kabupaten Bangka, yaitu di Kampoeng Reklamasi Air Jangkang Kecamatan Merawang. Penentuan lokasi ini dilakukan secara sengaja (Purposive) dengan pertimbangan bahwa lokasi ini merupakan salah satu kegiatan reklamasi oleh PT TIMAH Tbk yang ada di Kepulauan Bangka Belitung dengan konsep berbeda dari reklamasi lain yang ada di Bangka Belitung. Kampoeng Reklamasi ini merupakan reklamasi bentuk lain berupa 
agroeduwisata mengenai pengenalan dengan Satwa Bangka, Pertanian, Tanaman Lokal dan pembibitannya, Rumah Adat Bangka Belitung, serta Perikanan dengan sistem Biofloc. Metode penarikan contoh yang digunakan adalah Purposive Sampling dengan jumlah sampel sebesar 93 orang. Penelitian ini menggunakan jenis data primer dan data sekunder.

\section{Analisis Data}

Tujuan penelitian dianalisis menggunakan skala deskriptif dengan perhitungan skala Likert untuk mendeskripsikan persepsi masyarakat dan dampak sosial ekonomi terhadap lahan bekas tambang timah sebagai Kampoeng Reklamasi Air Jangkang. Skala Likert untuk mengukur sikap, pendapat, dan persepsi seseorang maupun sekelompok orang tentang fenomena sosial. Dengan mengunakan skala Likert, maka variabel yang akan diukur dijabarkan menjadi indikator variabel. Kemudian indikator variabel tersebut dijadikan sebagai titik tolak untuk menyusun item-item instrument yang dapat berupa pertanyaan atau pernyataan (Umar, 2011). Bobot penilaian skala Likert sebagai berikut:

Tabel 2. Bobot Penilaian Skala Likert

\begin{tabular}{lc}
\hline \multicolumn{1}{c}{ Keterangan } & Bobot \\
\hline Sangat Setuju & 5 \\
Setuju & 4 \\
Kurang Setuju & 3 \\
Tidak Setuju & 2 \\
Sangat Tidak Setuju & 1 \\
\hline Sumber: Sugiono $(2009)$
\end{tabular}

Sumber: Sugiono (2009)

Dalam penyelesaian perhitungan kriteria skala Likert diatas, yaitu menggunakan rumus sebagai berikut :

$$
\text { Rumus index } \%=\frac{\text { Total skor }}{y} \times 100
$$

Keterangan :

Total skor $=$ Total jumlah responden yang memilih

$\mathrm{Y}=$ Skor tertinggi (skala Likert $\mathrm{x}$ jumlah responden)
Setelah dilakukan perhitungan dengan rumus index $\%$ akan muncul hasil berupa presentase nilai dari skala Likert tersebut. Adapun koefisien perhitungan skala Likert secara rinci tersaji pada Tabel 3:

Tabel 3. Koefisien skala Likert

\begin{tabular}{|c|l|}
\hline Koefisien & Keterangan \\
\hline $0 \%-19,99 \%$ & $\begin{array}{l}\text { Sangat(tidak puas, } \\
\text { setuju sekali, } \\
\text { buruk) }\end{array}$ \\
\hline $20 \%-39,99 \%$ & $\begin{array}{l}\text { Tidak (puas, setuju, } \\
\text { atau tidak baik) }\end{array}$ \\
\hline $40 \%-59,99 \%$ & $\begin{array}{l}\text { Kurang puas, cukup } \\
\text { atau netral }\end{array}$ \\
\hline $60 \%-79,99 \%$ & $\begin{array}{l}\text { Puas, setuju, baik } \\
\text { atau suka }\end{array}$ \\
\hline $80 \%-100 \%$ & $\begin{array}{l}\text { Sangat (puas, } \\
\text { setuju, baik, suka) }\end{array}$ \\
\hline
\end{tabular}

\section{HASIL DAN PEMBAHASAN}

\section{Persepsi Masyarakat Terhadap Keberadaan Kampoeng Reklamasi Air Jangkang}

Persepsi suatu pandangan atau tanggapan oleh masyarakat sekitar Air Jangkang melalui indera-indera yang dimilikinya dalam diri individu, sehingga individu sadar atau paham segala sesuatu dalam lingkungannya. Persepsi ini melihat bagaimana tanggapan masyarakat terhadap keberadaan Kampoeng Reklamasi Air Jangkang dengan 3 aspek penilaian, yaitu persepsi terhadap tahapan pra reklamasi lahan bekas tambang sebagai Kampoeng Reklamasi, persepsi masyarakat terhadap tahap pelaksanaan program reklamasi pembangunan Kampoeng Reklamasi, dan persepsi masyarakat terhadap keberhasilan pembangunan Kampoeng Reklamasi. Untuk lebih rinci dapat dilihat sebagai berikut: 
Persepsi Masyarakat Terhadap Tahapan Pra Reklamasi Lahan Tambang Sebagai Kampoeng Reklamasi

Persepsi masyarakat terhadap tahapan pra reklamasi dilihat dari kegiatan PT TIMAH Tbk sebelum melakukan reklamasi. Persepsi ini untuk melihat bagaimana tanggapan masyarakat Desa
Riding Panjang terhadap kegiatan reklamasi yang dilakukan. Persepsi ini melihat setuju tidaknya kegiatan pra reklamasi yang dilakukan oleh PT TIMAH Tbk di Lahan Bekas Tambang sebagai Kampoeng Reklamasi. Semua hasil akan dipaparkan sebagai berikut:

Tabel 4. Nilai Skor Persepsi Masyarakat Terhadap Tahapan Pra Reklamasi Lahan Tambang Sebagai Kampoeng Reklamasi

\begin{tabular}{|c|c|c|c|c|c|}
\hline \multirow[t]{2}{*}{ No } & \multirow[t]{2}{*}{ Pernyataan } & \multirow[t]{2}{*}{ Indikator } & \multicolumn{3}{|c|}{ Responden } \\
\hline & & & Jumlah (orang) & Skor & Persentase (\%) \\
\hline \multirow[t]{5}{*}{1} & Masyarakat Desa Riding & SS & 33 & 165 & 35,5 \\
\hline & Panjang setuju dilakukan & $\mathrm{S}$ & 56 & 224 & 60,2 \\
\hline & reklamasi & $\mathrm{KS}$ & 4 & 12 & 4,3 \\
\hline & Kampoeng Reklamasi & TS & 0 & 0 & 0 \\
\hline & Air Jangkang. & STS & 0 & 0 & 0 \\
\hline \multirow[t]{5}{*}{2} & Masyarakat mengetahui & SS & 21 & 105 & 22,6 \\
\hline & program reklamasi di & $\mathrm{S}$ & 61 & 244 & 65,6 \\
\hline & Kampoeng Reklamasi & $\mathrm{KS}$ & 10 & 30 & 10,8 \\
\hline & oleh PT TIMAH Tbk. & TS & 1 & 2 & 1,1 \\
\hline & & STS & 0 & 0 & 0 \\
\hline \multirow[t]{5}{*}{3} & Masyarakat sekitar area & SS & 24 & 120 & 25,8 \\
\hline & reklamasi mendapatkan & $\mathrm{S}$ & 48 & 192 & 51,6 \\
\hline & sosialisasi oleh PT & $\mathrm{KS}$ & 18 & 54 & 19,4 \\
\hline & TIMAH Tbk sebelum & TS & 3 & 6 & 3,2 \\
\hline & $\begin{array}{l}\text { dilaksanakannya } \\
\text { kegiatan reklamasi. }\end{array}$ & STS & 0 & 0 & 0 \\
\hline \multirow[t]{5}{*}{4} & Masyarakat setuju & SS & 41 & 205 & 44,1 \\
\hline & dengan alih fungsi lahan & $\mathrm{S}$ & 43 & 172 & 46,2 \\
\hline & bekas tambang menjadi & $\mathrm{KS}$ & 8 & 24 & 8,6 \\
\hline & destinasi wisata. & TS & 1 & 2 & 1,1 \\
\hline & & STS & 0 & 0 & 0 \\
\hline \multirow[t]{10}{*}{5} & Pihak perusahaan & SS & 18 & 90 & 19,4 \\
\hline & berkoordinasi dengan & $\mathrm{S}$ & 53 & 212 & 57 \\
\hline & beberapa & KS & 17 & 51 & 18,3 \\
\hline & masyarakat & TS & 5 & 10 & 5,4 \\
\hline & seperti perangkat desa, & STS & 0 & 0 & 0 \\
\hline & kelompok tani atau & & & & \\
\hline & karang taruna untuk & & & & \\
\hline & program reklamasi apa & & & & \\
\hline & saja yang akan & & & & \\
\hline & dilakukan. & & & & \\
\hline \multirow[t]{5}{*}{6} & Keterlibatan masyarakat & $\mathrm{SS}$ & 31 & 155 & 33,3 \\
\hline & sekitar dalam kegiatan & $S$ & 45 & 180 & 48,4 \\
\hline & reklamasi & $\mathrm{KS}$ & 12 & 36 & 12,9 \\
\hline & & TS & 4 & 8 & 4,3 \\
\hline & & STS & 1 & 1 & 1,1 \\
\hline
\end{tabular}

Sumber. Olahan DataPrimer 2020 
Persentase persepsi terhadap pra reklamasi sebesar 82,4 persen Menurut Sugiono (2009) persentase 80\% - 100\% termasuk kategori sangat setuju. Hal ini menunjukkan bahwa masyarakat sangat setuju dengan pra reklamasi yg dilakukan pihak PT TIMAH. Karena mereka ikut dilibatkan dalam kegiatan reklamasi ini dan Kampoeng Reklamasi ini juga sebagai penunjang perekonomian masyarakat sekitar serta sebagai keberlangsungan dalam hal wisata, edukasi dan air bersih. Hal ini sejalan dengan penelitian Habibah (2019) menyatakan bahwa masyarakat menyatakan setuju dengan reklamasi, karena kegiatan reklamasi sudah menjadi bagian penting dari keberlangsungan desa baik dari hal air bersih, tempat wisata, dan lapangan pekerjaan.

\section{Persepsi Masyarakat Pada Tahap Pelaksaanaan Program Reklamasi Sebagai Kampoeng Reklamasi}

Persepsi yang akan diukur dalam penelitian ini, yaitu persepsi masyarakat setuju atau tidaknya terhadap program yang telah dilakukan di Kampoeng Reklamasi. Untuk lebih rinci dapat dilihat di Tabel 5:

Tabel 5. Nilai Skor Persepsi Masyarakat Pada Tahap Pelaksanaan Program Reklamasi Terhadap Pembangunan Kampoeng Reklamasi

\begin{tabular}{|c|c|c|c|c|c|}
\hline \multirow[t]{2}{*}{ No } & \multirow[t]{2}{*}{ Pernyataan } & \multirow[t]{2}{*}{ Indikator } & \multicolumn{3}{|c|}{ Responden } \\
\hline & & & Jumlah (orang) & Skor & $\begin{array}{l}\text { Persentase } \\
(\%)\end{array}$ \\
\hline \multirow[t]{5}{*}{1} & \multirow{5}{*}{$\begin{array}{l}\text { Program pembuatan PPS } \\
\text { (Pusat Penyelamatan Satwa) } \\
\text { seperti buaya, siamang, } \\
\text { musang,tarsius, beruang } \\
\text { madu, kuda, rusa, burung } \\
\text { dll di area reklamasi. }\end{array}$} & SS & 28 & 140 & 30,1 \\
\hline & & $S$ & 52 & 608 & 55,9 \\
\hline & & KS & 11 & 33 & 11,8 \\
\hline & & TS & 2 & 4 & 2,2 \\
\hline & & STS & 0 & 0 & 0 \\
\hline \multirow[t]{5}{*}{2} & \multirow{5}{*}{$\begin{array}{l}\text { Pembangunan rumah adat } \\
\text { Bangka Belitung di area } \\
\text { reklamasi. }\end{array}$} & SS & 27 & 135 & 29 \\
\hline & & $S$ & 50 & 200 & 53,8 \\
\hline & & KS & 13 & 39 & 14 \\
\hline & & TS & 3 & 6 & 3,2 \\
\hline & & STS & 0 & 0 & 0 \\
\hline \multirow[t]{5}{*}{3} & \multirow{5}{*}{$\begin{array}{l}\text { Program perkebunan yang } \\
\text { terdiri dari kebun buah } \\
\text { naga, jambu, jagung, } \\
\text { mangga, bunga matahari dll. }\end{array}$} & SS & 28 & 140 & 30,1 \\
\hline & & $S$ & 54 & 216 & 58,1 \\
\hline & & KS & 9 & 27 & 9,7 \\
\hline & & TS & 1 & 2 & 1,1 \\
\hline & & STS & 1 & 1 & 1,1 \\
\hline \multirow[t]{5}{*}{4} & \multirow{5}{*}{$\begin{array}{l}\text { Program peternakan yang } \\
\text { terdiri dari sapi, ayam, } \\
\text { kambing. }\end{array}$} & SS & 22 & 110 & 23,7 \\
\hline & & $S$ & 59 & 236 & 63,4 \\
\hline & & KS & 9 & 27 & 9,7 \\
\hline & & TS & 2 & 4 & 2,2 \\
\hline & & STS & 1 & 1 & 1,1 \\
\hline \multirow[t]{5}{*}{5} & \multirow{5}{*}{$\begin{array}{l}\text { Program } \\
\text { greenhouse. }\end{array}$} & SS & 18 & 90 & 19,4 \\
\hline & & $S$ & 53 & 212 & 57 \\
\hline & & KS & 19 & 57 & 20,4 \\
\hline & & TS & 3 & 6 & 3,2 \\
\hline & & STS & 0 & 0 & 0 \\
\hline
\end{tabular}




\begin{tabular}{|c|c|c|c|c|c|}
\hline 6 & $\begin{array}{l}\text { Program penanaman } \\
\text { tanaman fastgrowing. }\end{array}$ & $\begin{array}{c}\text { SS } \\
\text { S } \\
\text { KS } \\
\text { TS } \\
\text { STS }\end{array}$ & $\begin{array}{r}14 \\
54 \\
18 \\
6 \\
0\end{array}$ & $\begin{array}{r}70 \\
216 \\
54 \\
12 \\
0\end{array}$ & $\begin{array}{r}15,1 \\
58,1 \\
19,4 \\
6,5\end{array}$ \\
\hline 7 & \begin{tabular}{lrr} 
Program & \multicolumn{2}{c}{ pengembangan } \\
perikanan & dengan & sistem \\
biofloc. & &
\end{tabular} & $\begin{array}{c}\text { SS } \\
\text { S } \\
\text { KS } \\
\text { TS } \\
\text { STS }\end{array}$ & $\begin{array}{r}17 \\
56 \\
18 \\
0 \\
2\end{array}$ & $\begin{array}{r}85 \\
224 \\
54 \\
0 \\
2\end{array}$ & $\begin{array}{r}18,3 \\
60,2 \\
19,4 \\
0 \\
2,2\end{array}$ \\
\hline 8 & $\begin{array}{l}\text { Program pengembangan } \\
\text { wisata air di area reklamasi. }\end{array}$ & $\begin{array}{c}\text { SS } \\
\text { S } \\
\text { KS } \\
\text { TS } \\
\text { STS }\end{array}$ & $\begin{array}{r}46 \\
42 \\
4 \\
1 \\
0\end{array}$ & $\begin{array}{r}230 \\
168 \\
12 \\
2 \\
0\end{array}$ & $\begin{array}{r}49,5 \\
45,2 \\
4,3 \\
1,1 \\
0\end{array}$ \\
\hline 9 & \begin{tabular}{lr} 
Program & \multicolumn{2}{r}{ penanaman } \\
tanaman lokal & seperti \\
pelawan, nyatoh.
\end{tabular} & $\begin{array}{c}\text { SS } \\
\text { S } \\
\text { KS } \\
\text { TS } \\
\text { STS }\end{array}$ & $\begin{array}{r}29 \\
55 \\
6 \\
3 \\
0\end{array}$ & $\begin{array}{r}145 \\
220 \\
18 \\
6 \\
0\end{array}$ & $\begin{array}{r}31,2 \\
59,1 \\
6,5 \\
3,2 \\
0\end{array}$ \\
\hline 10 & $\begin{array}{l}\text { Program penanaman secara } \\
\text { hidroponik. }\end{array}$ & $\begin{array}{c}\text { SS } \\
\text { S } \\
\text { KS } \\
\text { TS } \\
\text { STS }\end{array}$ & $\begin{array}{r}18 \\
57 \\
17 \\
1 \\
0\end{array}$ & $\begin{array}{r}90 \\
228 \\
51 \\
2 \\
0\end{array}$ & $\begin{array}{r}19,4 \\
61,3 \\
18,3 \\
1,1 \\
0\end{array}$ \\
\hline
\end{tabular}

Sumber. Olahan Data Primer 2020

Persepsi masyarakat pada tahap pelaksaanaan program reklamasi terhadap pembangunan Kampoeng Reklamasi sebesar 81,4 persen. Menurut Sugiono (2009) 80\%-100\% termasuk kategori sangat setuju. Masyarakat sangat setuju dengan program yang dilakukan oleh pihak PT TIMAH. Karena program yang dijalankan bermanfaat bagi pengunjung ataupun masyarakat sekitar. Kampoeng Reklamasi ini dapat menjadi destinasi wisata yang bernilai edukasi. Pengunjung tidak hanya bisa melihat kolong bekas tambang, tetapi juga bisa melihat flora dan fauna yang terdapat di Kampoeng Reklamasi.

\section{Persepsi Masyarakat Terhadap Keberhasilan Reklamasi Sebagai Kampoeng Reklamasi.}

Persepsi ini melihat bagaimana tanggapan masyarakat terhadap tingkat keberhasilan reklamasi lahan bekas tambang di Kampoeng Reklamasi Air Jangkang. Untuk lebih rinci dapat dilihat di Tabel 6 berikut: 
Tabel 6. Nilai Skor Persepsi Masyarakat Terhadap Keberhasilan Pembangunan Kampoeng Reklamasi

\begin{tabular}{llccccc}
\hline No & \multicolumn{2}{c}{ Pernyataan } & Indikator & \multicolumn{3}{c}{ Responden } \\
\cline { 3 - 6 } & & & Jumlah (orang) & Skor & Persentase (\%) \\
\hline \multirow{2nyyyy}{n}{} & & Kampoeng reklamasi & SS & 48 & 240 & 51,6 \\
& membuat & lahan & S & 33 & 132 & 35,5 \\
& menjadi & lebih & KS & 12 & 36 & 12,9 \\
& & TS & 0 & 0 & 0 \\
& & produktif. & STS & 0 & 0 & 0 \\
\hline 2 & Kampoeng reklamasi & SS & 54 & 270 & 58,1 \\
& sebagai & wisata & S & 32 & 128 & 34,4 \\
& edukasi & bagi & KS & 6 & 18 & 6,5 \\
& masyarakat & lokal & TS & 1 & 2 & 1,1 \\
& maupun luar. & STS & 0 & 0 & 0 \\
\hline
\end{tabular}

Sumber: Olahan Data Primer 2020

Persentase keberhasilan

pembangunan Kampoeng Reklamasi sebesar 88,8 persen Menurut Sugiono (2009) persentase $80 \%-100 \%$ termasuk kategori sangat setuju. Masyarakat sangat setuju dengan keberhasilan reklamasi di Kampoeng Reklamasi, karena Kampoeng Reklamasi dapat membuat lahan menjadi produktif dan bisa sebagai wisata yang bernilai edukasi bagi masyarakat. Dengan keberadaan Kampoeng Reklamasi lahan yang dulunya kritis sekarang bisa ditanami tanaman dan dapat menambah pendapatan masyarakat sekitar. Selain dapat menunjang perekonomian Kampoeng Reklamasi juga dapat menjadi wisata edukasi bagi masyarakat baik pertanian, peternakan, perikanan maupun PPS.

\section{Dampak Sosial Ekonomi Masyarakat Terhadap Keberadaan Kampoeg Reklamasi Air Jangkang \\ Dampak sosial ekonomi ini melihat} bagaimana pengaruh atau akibat terhadap masyarakat dengan adanya kampoeng reklamasi Air Jangkang. Hal ini mengukur seberapa besar dampak positif yang diberikan dari kegiatan reklamasi terhadap lingkungan masyarakat sekitar area reklamasi. Dampak sosial ekonomi masyarakat terdiri dari:

\section{Dampak Sosial Masyarakat Terhadap Keberadaan Kampoeng Reklamasi}

Keberadaan Kampoeng Reklamasi ini akan memberikan dampak yang terjadi di masyarakat. Dalam penelitian ini akan dilihat dampak sosial yang terdiri dari keamanan dan kondisi lingkungan hidup. Untuk lebih jelas dapat dilihat di Tabel 7 dibawah ini: 
Tabel 7. Nilai Skor Dampak Sosial Masyarakat Terhadap Keberadaan Kampoeng Reklamasi

\begin{tabular}{|c|c|c|c|c|c|}
\hline \multirow[t]{2}{*}{ No. } & \multirow[t]{2}{*}{ Pernyataan } & \multirow[t]{2}{*}{ Indikator } & \multicolumn{3}{|c|}{ Responden } \\
\hline & & & Jumlah (orang) & Skor & Persentase $(\%)$ \\
\hline 1 & $\begin{array}{l}\text { Keberadaan Kampoeng } \\
\text { Reklamasi menurunkan } \\
\text { tingkat keamanan masyarakat } \\
\text { sekitar area reklamasi. }\end{array}$ & $\begin{array}{l}\text { SS } \\
\text { S } \\
\text { KS } \\
\text { TS } \\
\text { STS }\end{array}$ & $\begin{array}{r}18 \\
26 \\
30 \\
13 \\
6\end{array}$ & $\begin{array}{r}90 \\
104 \\
90 \\
26 \\
6\end{array}$ & $\begin{array}{r}19,35 \\
27,96 \\
32,3 \\
14 \\
6,5\end{array}$ \\
\hline 2 & 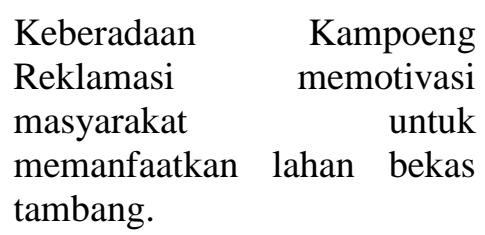 & $\begin{array}{l}\text { SS } \\
\text { S } \\
\text { KS } \\
\text { TS } \\
\text { STS }\end{array}$ & $\begin{array}{r}17 \\
47 \\
24 \\
4 \\
1\end{array}$ & $\begin{array}{r}85 \\
188 \\
72 \\
8 \\
1\end{array}$ & $\begin{array}{r}18,3 \\
50,5 \\
25,8 \\
4,3 \\
1,1\end{array}$ \\
\hline 3 & $\begin{array}{lr}\text { Kegiatan } & \text { reklamasi } \\
\text { mengurangi } & \text { tingkat } \\
\text { pencemaran air kolong di Air } \\
\text { Jangkang. }\end{array}$ & $\begin{array}{c}\text { SS } \\
\text { S } \\
\text { KS } \\
\text { TS } \\
\text { STS }\end{array}$ & $\begin{array}{r}8 \\
47 \\
26 \\
8 \\
4\end{array}$ & $\begin{array}{r}40 \\
188 \\
78 \\
16 \\
4\end{array}$ & $\begin{array}{r}8,6 \\
50,5 \\
28 \\
8,6 \\
4,3\end{array}$ \\
\hline 4 & $\begin{array}{l}\text { Kampoeng Reklamasi } \\
\text { menjadi sumber air bersih di } \\
\text { musim kemarau. }\end{array}$ & $\begin{array}{c}\text { SS } \\
\text { S } \\
\text { KS } \\
\text { TS } \\
\text { STS }\end{array}$ & $\begin{array}{r}9 \\
37 \\
33 \\
10 \\
4\end{array}$ & $\begin{array}{r}45 \\
148 \\
99 \\
20 \\
4\end{array}$ & $\begin{array}{r}9,7 \\
39,8 \\
35,5 \\
10,8 \\
4,3\end{array}$ \\
\hline
\end{tabular}

Sumber: Olahan Data Primer 2020

Persentase dampak sosial sebesar 70,5 persen. Hal ini menyatakan berdampak positif sejalan dengan penelitian Rina Ulfa (2016) menyatakan persentase 60\% - 100\% bermakna positif. Dengan kegiatan reklamasi dengan pemanfaatan lahan bekas tambang timah tidak hanya dapat memperbaiki kondisi lingkungan akibat aktivitas penambangan tetapi juga memperhatikan keamanan masyarakat sekitar. Oleh karena itu, kegiatan reklamasi yang dapat memberikan dampak yang positif bagi masyarakat setempat dalam hal memulihkan kehidupan sosialnya, dapat menjadi salah satu indikator keberhasilan reklamasi. Hal ini sejalan dengan penelitian
Asmarhansyah dan Rahmat Hasan (2016), menyatakan kegiatan reklamasi tidak sebaiknya difokuskan pada perbaikan lingkungan bekas tambang timah, namun harus juga memperhitungkan kehidupan sosial ekonomi masyarakat.

\section{Dampak Ekonomi Masyarakat Terhadap Keberadaan Kampoeng Reklamasi Dampak ekonomi yang diidentifikasi dalam penelitian ini adalah perubahan tingkat pendapatan dan penyerapan tenaga kerja masyarakat. Untuk lebih jelas dapat dilihat di Tabel 8 dibawah ini.}


ISSN No 2086-7956 E-ISSN No 2615-5494

Tabel 8. Nilai Skor Dampak Ekonomi Masyarakat Terhadap Keberadaan Kampoeng Reklamasi

\begin{tabular}{|c|c|c|c|c|c|}
\hline \multirow[t]{2}{*}{ No } & \multirow[t]{2}{*}{ Pernyataan } & \multirow[t]{2}{*}{ Indikator } & \multicolumn{3}{|c|}{ Responden } \\
\hline & & & Jumlah (orang) & Skor & Persentase (\%) \\
\hline \multirow[t]{5}{*}{1} & Keberadaan kampoeng & SS & 30 & 150 & 32,3 \\
\hline & reklamasi & $\mathrm{S}$ & 39 & 156 & 41,9 \\
\hline & meningkatkan & $\mathrm{KS}$ & 21 & 63 & 22,6 \\
\hline & pendapatan masyarakat. & TS & 3 & 6 & 3,2 \\
\hline & & STS & 0 & 0 & 0 \\
\hline \multirow[t]{5}{*}{2} & Keberadaan kampoeng & SS & 20 & 100 & 21,5 \\
\hline & reklamasi & $\mathrm{S}$ & 43 & 172 & 46,2 \\
\hline & memenuhi pangan, papan & $\mathrm{KS}$ & 24 & 72 & 25,8 \\
\hline & dan sandang masyarakat & TS & 4 & 8 & 4,3 \\
\hline & Air Jangkang. & STS & 2 & 2 & 2,2 \\
\hline \multirow[t]{5}{*}{3} & Keberadaan & SS & 22 & 110 & 23,7 \\
\hline & reklamasi & $\mathrm{S}$ & 51 & 204 & 54,8 \\
\hline & kesempatan & $\mathrm{KS}$ & 16 & 48 & 17,2 \\
\hline & dan lapangan pekerjaan. & TS & 4 & 8 & 4,3 \\
\hline & & STS & 0 & 0 & 0 \\
\hline \multirow[t]{5}{*}{4} & keberadaan & SS & 25 & 125 & 26,9 \\
\hline & kampoeng reklamasi bisa & $\mathrm{S}$ & 50 & 200 & 53,8 \\
\hline & menyerap tenaga kerja & $\mathrm{KS}$ & 15 & 45 & 16,1 \\
\hline & dari masyarakat Air & TS & 2 & 4 & 2,2 \\
\hline & Jangkang. & STS & 1 & 1 & 1,1 \\
\hline
\end{tabular}

Sumber: Olahan Data Primer 2020

dengan penelitian Rina Ulfa (2016) menyatakan persentase $60 \%$ - $100 \%$ bermakna positif. Dengan adanya kegiatan reklamasi ini dapat meningkatkan pendapatan masyarakat karena adanya penyerapan tenaga kerja untuk masyarakat sekitar area reklamasi. Kegiatan reklamasi yang mampu memberikan manfaat bagi masyarakat sekitar untuk berusaha tani di lahan bekas tambang timah dapat dijadikan sebagai salah satu indikator keberhasilan reklamasi pasca tambang. Hal ini sejalan dengan penelitian dari Asmarhansyah dan Rahmat Hasan (2016), menyatakan lahan bekas tambang timah berpeluang untuk dimanfaatkan sebagai areal pertanian dalam upaya pemenuhan kebutuhan pangan dan mengatasi kehidupan sosial ekonomi masyarakat setempat.

\section{KESIMPULAN}

Persepsi masyarakat terhadap lahan bekas tambang timah sebagai Kampoeng Reklamasi menyatakan sangat setuju pada indikator tahapan pra reklamasi lahan bekas tambang sebagai Kampoeng Reklamasi, tahap pelaksanaan program reklamasi terhadap pembangunan Kampoeng Reklamasi dan keberhasilan serta dampak sosial ekonomi masyarakat terhadap keberadaan Kampoeng Reklamasi menyatakan berdampak positif terhadap masyarakat sekitar area reklamasi. 


\section{DAFTAR PUSTAKA}

Akbarini, Dian. 2016. Spesies Kunci Keberlanjutan Hutan Taman Keanekaragaman Hayatai Namang, Bangka Tengah. Jurnal Biologi. Vol 9. No.1.

Asmarhansyah dan Rahma Hasan. 2016.

Reklamasi Lahan Bekas Tambang Timah Sebagai Lahan Pertanian di Keulauan Bangka Belitung. Prosiding Seminar Nasional Agroinovasi Spesifik Lokasi Untuk Ketahanan Pangan Pada Era Masyarakat Ekonomi ASEAN.

Badan Pusat Statistika Provinsi Kepulauan Bangka Belitung. 2017. Lahan Kritis Bangka Belitung. Pangkalpinang.

Fitri, R H., 2016. Restorasi Pasca Tambang Timah Pulau Bangka. Jurnal Society. Vol 6 No1.

Hira Delta Saputri dan Rika Harini. 2017. Persepsi Masyarakat Terhadap Dampak Pertambangan Batubara Pada Kondisi Sosial Ekonomi Masyarakat di Kecamatan Talawi, Sawahlunto, Sumatera Barat. Prosiding Teknik Pertambangan. Vol.3. No.2.

Inonu, Ismed. 2013. Pengelolaan Lahan Tailing Timah di Pulau Bangka. Universitas Sriwijaya. Jurnal

Iskandar. 2008. Rehabilitas Kerusakan Lahan Akibat Kegiatan Tambang. Fakultas Pertanian:IPB.

Peraturan Menteri Negara Lingkungan Hidup Nomor 04 Tahun 2012 Tentang Indikator Ramah Lingkungan Untuk Usaha dan atau Kegiatan Penambangan Terbuka Batubara.

Permen ESDM Nomor 07 Tahun 2014 Tentang Pelaksanaan Reklamasi dan Pascatambang Pertambangan Mineral dan Batubara.

Projosumarto.P, 2006, Teknik Reklamasi Pada Lahan Bekas Tambang, Sekolah Tinggi Teknologi Nasional Yogyakarta

PT Adaro Indonesia. 2009. Laporan Pelaksanaan RKL/RPL. Triwulan II Tahun 2009 Tambang Tutupan. Kalimantan Selatan.

PT Timah Tbk. 2017. Arsip Reklamasi Lahan. Bangka Belitung

PT Timah Tbk. 2017. Laporan Tahunan PT Timah Tbk Tahun 2017. Bangka Belitung.

Rr Diah Nugrahaeni dkk. 2017. Studi pemilihan Tanaman Revegetasi Untuk Keberhasilan Lahan Bekas Tambang. Jurnal Teknik Lingkungan. Vol 3. No.1.

Sugiono. 2010. Metode Penelitian Pendidikan Pendekatan Kualitatif, Kuantitatif dan RD. Bandung: Alfabeta.

Umar, Husein. 2011. Metode Penelitian Untuk Skripsi dan Tesis Bisnis. Edisi Kedua, Jakarta: PT Raja Grafindo Persada 